\title{
A CARTOMANTE: UMA TRAGICOMÉDIA MACHADIANA
}

\author{
Dário Ferreira Sousa Neto \\ Universidade de São Paulo \\ São Paulo (SP), Brasil
}

\begin{abstract}
Ao Prof. Dr. João Adolfo Hansen, pela orientação e pelas valiosas discussões que muito contribuíram para o desenvolvimento deste trabalho.
\end{abstract}

\begin{abstract}
Resumo: As narrativas de Machado de Assis incluem-se na tradição literária da ficção tragicômica. A mistura dos estilos trágico e cômico que caracteriza seus textos principais torna a literatura brasileira nova por meio da ironia de uma enunciação paródica, que inverte as significações usuais das representações burguesas. Em "A cartomante", Camilo, Rita e Vilela formam um triângulo amoroso que cita histórias românticas publicadas nos jornais à época do autor. Usando-as como material de uma estética literária na qual o estilo trágico figura coisas cômicas, e o cômico é sério, Machado dá novas e inesperadas significações aos elementos do melodrama burguês como casamento, amantes, adultério e morte -, criticando a normalidade dos padrões sociais de representação da sua sociedade.
\end{abstract}

Palavras-chave: tragicomédia; paródia; ironia.

\section{"A cartomante": a Machadian tragicomedy}

Abstract: The fiction of Machado de Assis is inscribed in a literary tradition in which the concept of tragicomedy plays an important role. The mixture of tragic and comic styles that characterise his most important texts innovates Brazilian literature by means of irony and parody to invert the usual meanings of bourgeois representations. In "A cartomante" ["The fortune teller"], Camilo, Rita and Vilela form a triangle, which alludes to the typical romantic plot, extensively used in newspapers publications of the time. Using them as material for a literary aesthetics in which tragic style is used to represent comic things and comic is serious, Machado gives new and unexpected meanings to the elements of bourgeois melodrama - such as marriage, lovers, adultery and death -, criticising the normality of social patterns of representation of his society.

Keywords: tragicomedy; parody; irony. 
No Prólogo da peça Anfitrião, ${ }^{1}$ de Plauto, o deus Mercúrio observa à plateia o gênero da obra que será apresentada. A peça é essencialmente uma comédia, pois pretende divertir. Contudo, por ter a participação de deuses, a peça deveria ser uma tragédia. Por ser uma encenação que objetiva a diversão do público, mas que trata de personagens elevadas, a peça é definida por Mercúrio como uma tragicomédia. Esse gênero misto caracteriza-se pela ambivalência dramática da harmonia dos contrastes (concórdia e discórdia, afetos altos e baixos), seja nas formas da recepção, provocando no leitor/ouvinte sentimentos dúbios de riso e compaixão, seja nas formas da composição, em que o texto articula o sério e o jocoso, o baixo e o sublime, reacentuando seus aspectos de modo que o cômico se torne mais cômico, e o sério, mais sério:

$\mathrm{Na}$ sintonia com a unidade da natureza que se desdobra na multiplicidade das suas criações, o poeta tragicômico se compraz na mobilidade pura, que o faz passar "da seriedade ao riso, das excitações cômicas às emoções dilacerantes" e que o singulariza como ser que contém em si mesmo os contrários. ${ }^{2}$

Entender a junção da tragédia e da comédia exige a compreensão da estrutura desses gêneros e sua aplicação na fortuna literária. A rearticulação no drama moderno de suas formas próprias faz-se acompanhar de procedimentos da paródia e da ironia, que lhes reavivam as tessituras. Para Melo e Souza, a representação desse gênero misto reforça uma divergência convergente ou convergência divergente, que suscita emoções discordantes e, ao mesmo tempo, complementares.

\footnotetext{
${ }^{1}$ PLAUTUS, Titus Maccius. Anfitrião. Lisboa: Edições 70, 1993.

${ }^{2}$ SOUZA, Ronaldes de Melo e. O romance tragicômico de Machado de Assis. Rio de Janeiro: EdUERJ, 2006. p. 64.
} 
As formas de composição do trágico constituem-se na unidade de salvação e aniquilamento do herói frente ao destino. ${ }^{3}$ Para Schelling, "a tragédia grega honrava a liberdade humana ao fazer o herói lutar contra o poder superior do destino". ${ }^{4}$ Nessa relação dialética de salvação e aniquilamento, na qual um porta necessariamente o outro, o destino apresenta-se como fatalidade sobre o herói que o desafiará, mas que está condenado a sucumbir à sua força. $\mathrm{O}$ destino manifesta-se e se concretiza por meio de seu porta-voz: o oráculo. Diante da profecia, o herói toma conhecimento de sua tragédia e dispõe-se a escapar de sua sina. Para isso, utiliza-se de meios menos trágicos, recurso que Szondi define como "inconsequência". Ao referir-se à Poética de Aristóteles, Ivo C. Bender observa que

Aristóteles afirma que "as ações e o mito constituem a finalidade da tragédia e a finalidade é de tudo o que mais importa". Portanto, o mito ou enredo participando das duas definições apresenta-se como um dos elementos fundamentais da narrativa dramática. ${ }^{5}$

Mito, destino, heróis e oráculo tornam-se elementos constituintes de composição, enquanto impulso mimético da natureza, característica de origem da arte na tragédia; reconhecimento, profecia, desafio, inconsequência, salvação e aniquilamento são a tessitura da ação trágica, como efeitos da catarse; mimese e catarse são definidas como elementos que fundamentam o trágico na Poética de Aristóteles. ${ }^{6}$

No epítome "Tractatus Coislinianus", atribuído a Aristóteles, ${ }^{7}$ a comédia é definida como composição desprovida de grandeza e voltada para uma ação risível. Segundo Bender, a ausência de grandeza na comédia resulta de sua ação absurda. Bender apresenta, a partir do epítome, algumas características que a definem. São elas: pequenas ações encadeadas que desembocam na ação principal, característica comum tanto da tragédia quanto da comédia; o rebaixamento das personagens; o pensamento ou dianoia desenvolvido de modo inconsequente e absurdo. Disso resulta a possibilidade de

\footnotetext{
${ }^{3}$ SZONDI, Peter. Ensaio sobre o trágico. Rio de Janeiro: Jorge Zahar Ed., 2004.

${ }^{4}$ Cf. SZONDI, Peter. Ensaio sobre o trágico, cit., p. 29.

5 BENDER, Ivo C. Comédia e riso: uma poética do teatro cômico. Porto Alegre: EDIPUCRS, 1996. p. 21.

${ }^{6}$ ARISTÓTELES. Poética. São Paulo: Ed. Cultrix, 1981.

7 ARISTÓTELES. Tratado Coisliniano. In: Poética. Tradução feita pelo grupo de pesquisa do projeto OUSIA. Coord. Prof. Dr. Fernando Santoro. Disponível online no endereço:

<http://www.ifcs.ufrj.br/ fsantoro/ousia/traducao_coisliniano.html> (Acessado em 12 de março de 2008).
} 
o texto cômico provocar o riso por meio do absurdo, assim como a tragédia provoca as emoções por meio da catarse. Ainda tratando do texto de Aristóteles, Bender apresenta alguns elementos retóricos que possibilitam o riso. Alguns deles são: o engano, coisas ou eventos contrários à expectativa da plateia, as escolhas erradas etc. Observa também a importância do outro na composição da personagem cômica:

[...] na comédia, o outro é presença constante, e de sua existência podem brotar algumas das mais recorrentes peripécias que têm marcado o gênero. Além disso, o herói cômico dificilmente age sozinho: criados, escravos, irmãos gêmeos, parentes ou amigos servem como duplos ou, então, como cúmplices na obtenção do objetivo do protagonista. ${ }^{8}$

No "Tractatus Coislinianus", 9 Aristóteles observa três fases da comédia: Antiga - que se excede no risível; Nova - que o dispensa e se inclina para o sério; Média - que é uma mistura de ambas. O gênero tragicômico, característico da narrativa moderna, parece movimentar-se por entre a fase nova e a fase média. De qualquer modo, caracteriza-se pela ambivalência dos dois gêneros - tragédia e comédia - apresentados anteriormente. Entendendo a tragicomédia como forma de composição da narrativa moderna por meio da dramatização ambivalente e tensa entre sentimentos e sensações opostas, ${ }^{10}$ percebem-se alguns procedimentos que se incorporam na constituição desse gênero composicional. O primeiro deles é a imitatio, na compreensão renascentista do conceito, pela qual o poeta emula as autoridades dos diversos gêneros ao buscar um modelo para sua realização artística; o segundo é a paródia, enquanto desconstrução e reconstrução de uma nova dramatização narrativa. ${ }^{11}$ Esse procedimento não se limita à reconstrução do novo, mas à atribuição de novos significados à autoridade parodiada, constituindo uma face dupla para o mesmo tema. O terceiro procedimento é a ironia, enquanto procedimento de significado dito e não dito, que cria um terceiro, compondo-o como superposição de significados:

\footnotetext{
${ }^{8}$ BENDER, Ivo C. Comédia e Riso: uma poética do teatro cômico, cit., p. 39.

${ }^{9}$ ARISTÓTELES. Tratado Coisliniano, cit.

${ }^{10}$ SOUZA, Ronaldes de Melo e. O romance tragicômico de Machado de Assis, cit.

${ }^{11}$ HUTCHEON, Linda. Uma teoria da paródia: ensinamentos das formas de arte do século XX. Lisboa: Edições 70, 1989.
} 
Para invocar uma outra imagem, essa pode ser uma versão do que, em música, se chama voz tríplice: "Duas notas tocadas juntas produzem uma terceira nota que é, ao mesmo tempo, ambas e nenhuma delas". A ironia, então, compartilha com os trocadilhos uma simultaneidade e uma superposição de significados. ${ }^{12}$

Em "A cartomante", o narrador machadiano incorpora os aspectos formais do tragicômico, à medida que utiliza as estruturas da tragédia para tratar de um melodrama burguês vivido pelas personagens Camilo, Rita e Vilela. A referência à tragédia, na qual evidencia o procedimento da imitatio no texto, recuperando a peça de Shakespeare, mostra-se quando o narrador cita Hamlet, mas ressalta sua natureza melodramática ao tratar do triângulo amoroso de um adultério:

Hamlet observa a Horácio que há mais cousas no céu e na terra do que sonha a nossa filosofia. Era a mesma explicação que dava a bela Rita ao moço Camilo, numa sexta-feira de novembro de 1869, quando este ria dela, por ter ido na véspera consultar uma cartomante; a diferença é que o fazia por outras palavras [...] Foi então que ela, sem saber que traduzia Hamlet em vulgar, disse-lhe que havia muita coisa misteriosa e verdadeira neste mundo. ${ }^{13}$

A citação explícita de um trecho da peça evidencia a imitatio, que opera por meio da estruturação similar à da tragédia ática, que a peça de Shakespeare imita. $O$ destino é o amor entre Camilo e Rita, e quem o "profetiza" é a cartomante. Procurada primeiro por Rita e depois por Camilo, ela se configura como oráculo. Destino, profecia, personagens e oráculo, elementos da invenção trágica, são recuperados pela narrativa machadiana e, em seu desenvolvimento, reorganizados por meio da paródia.

O destino apresenta-se como clandestinidade do amor proibido de Camilo e Rita. Ela é casada com Vilela, amigo de infância de Camilo, mas a narrativa não nos apresenta essas informações de imediato. $\mathrm{O}$ texto inicia com a referência à cartomante consultada por Rita e sua suposta profecia - que não é explicitada, mas apenas insinuada - da possibilidade do relacionamento entre os dois. É importante observar que, stricto sensu, não há profecia no início, apenas Rita consulta a cartomante para

\footnotetext{
${ }^{12}$ HUTCHEON, Linda. Teoria e politica da ironia. Belo Horizonte: Editora UFMG, 2000. p. 93.

13 ASSIS, Machado de. A cartomante. In: Obras completas em quatro volumes. v. 2, Rio de Janeiro: Aguilar, 2008. p. 447. Grifo nosso.
} 
saber sobre o sentimento de Camilo por ela, o qual é confirmado pela vidente como verdadeiro. A insinuação de continuidade desse relacionamento, o que caracterizaria a profecia, não é feita textualmente, mas resulta da inferência do leitor que é provocada pelo narrador.

Se, no início da narrativa, o oráculo é apenas ponto de referência para a trama de Rita e Camilo, sua participação acontece quando este recebe um recado de Vilela solicitando-lhe ir com urgência à sua casa. Parodiando o dilema shakespeariano do "to be or not to be" como o "ir ou não ir" da indecisão de Camilo, que retoma e revive o drama do príncipe dinamarquês, ${ }^{14}$ o destino interfere e coloca o descrente diante do "Templo de Delfos". Preso a esse dilema e ansioso por saber as reais intenções do amigo traído, Camilo busca a cartomante, que lhe faz a profecia necessária para tranquilizá-lo e continuar seu caminho. Se, na tragédia edipiana, Laio tenta alterar o destino por meio da ação inconsequente, se Édipo desiste de procurar os pais ao saber da profecia de Delfos, Camilo tranquiliza-se diante da profecia e se apega a ela como forma de superação de seu dilema:

Tudo lhe parecia agora melhor, as outras cousas traziam outro aspecto, o céu estava límpido e as caras, joviais. Chegou a rir dos seus receios, que chamou pueris; recordou os termos da carta de Vilela e reconheceu que eram íntimos e familiares. Onde é que ele lhe descobrira a ameaça? Advertiu também que eram urgentes, e que fizera mal em demorar-se tanto; podia ser algum negócio grave e gravíssimo. ${ }^{15}$

A imitatio da tragédia opera-se no regulamento estrutural da narrativa: a personagem diante do templo toma conhecimento de seu destino e depois segue até o local onde acontecerá a catástrofe, na qual sucumbirá. Contudo, a paródia se estabelece como desvirtuamento do que é determinante para a constituição da tragédia. Em Édipo $R e i$, tanto Laio quanto Édipo, ao tomarem conhecimento de seu destino, enfrentam-no de modo inconsequente na tentativa de alterá-lo. Essa tensão é a garantia do status de herói, pois na busca de sua liberdade o herói desafia o destino, afirmando a necessidade

\footnotetext{
${ }^{14}$ VILLAÇA, Alcides. Machado de Assis: tradutor de si mesmo. In: Revista Novos Estudos, n. 51, julho de 1998. São Paulo, 1998. p. 3-14.

${ }^{15}$ ASSIS, Machado de. A cartomante, cit., p. 138.
} 
de, mesmo sucumbindo, não permitir o desfecho predeterminado sem luta. Na perda dessa liberdade, pode prová-la, mesmo perecendo, pois na luta faz sua declaração de vontade livre. ${ }^{16}$ Ambos fogem do destino para evitar que este se cumpra, mas é na fuga que o destino se confirma. Camilo, ao ter conhecimento da profecia, ao contrário dos outros, tranquiliza-se e continua sua trajetória até a casa de Vilela. Diferentemente dos dois personagens gregos, Camilo aposta e, por isso, torna-se crente na profecia. É exatamente essa crença que o leva a sucumbir assassinado pelo amigo traído. A paródia se estabelece pela profecia não trágica: a cartomante prevê para o amante de Rita um final feliz, segundo o modelo dos romances de folhetins. Ao fazer-lhe essa previsão, não apenas o leva à morte, como lhe subtrai o estatuto de herói na acepção trágica. Camilo não desafia o destino, não por covardia ou por não ter o caráter ético-estético necessário para constituir-se como herói, mas por não haver a necessidade de enfrentá-lo, uma vez que a profecia corresponde aos seus anseios e expectativas de futuro:

O essencial da tragédia é [...] um conflito real entre a liberdade do sujeito e a necessidade, como necessidade objetiva. Esse conflito não termina com a derrota de uma ou de outra, mas pelo fato de ambas aparecerem indiferentemente como vencedoras e vencidas. ${ }^{17}$

Como observa Schelling, na citação de Szondi, o conflito entre a liberdade do sujeito e a necessidade objetiva é o que constitui o essencial da tragédia. Se, em Édipo $R e i$, tanto Laio como Édipo necessitam fugir do destino, em Hamlet, o príncipe dinamarquês necessita vingar a morte do pai. Em "A cartomante", falta a Camilo a necessidade objetiva para constituir-se como herói e constituir a narrativa como tragédia. Essa ausência de necessidade deve-se ao esvaziamento do sentido transcendente da competência da cartomante em prever o futuro e da relação meramente mercantil em que dá ao cliente bem vestido o que ele quer. Machado rebaixa a função religiosa, que na tragédia antiga fundamenta a relação do oráculo com o herói, tornando-a relação de vendedor e cliente e estabelecendo uma nova ordem, que destrói o antigo fundamento mítico. Em contraponto a esse valor transcendente, característico de uma cultura como a grega, fundada no mito e na religião, o autor coloca-nos diante da

\footnotetext{
${ }^{16}$ SZONDI, Peter. Ensaio sobre o trágico, cit., p. 29.

${ }^{17}$ Idem, p. 31.
} 
nova lógica cultural da sociedade moderna: o fetichismo das relações capitalistas, em que o sagrado se transforma em mercadoria de consumo. Nesse procedimento em que se esvazia o valor transcendente, para preenchê-lo em uma nova lógica, o elemento da sina, na narrativa, é determinado pela participação do outro juntamente com a personagem protagonista e não pela sibila fetichista representada pela italiana. Rita, ao saber dos recados anônimos que Camilo vem recebendo, prontifica-se a levar consigo o bilhete para compará-lo às cartas que lhes chegavam a casa e, com isso, impedir que Vilela venha a saber da traição. Ao dar-nos essa informação, o narrador insinua a responsabilidade da moça na descoberta da traição por Vilela, uma vez que o aproximou dos sobrescritos. O narrador apenas apresenta a ação, deixando a cargo do leitor as possibilidades de leitura:

Nem por isso Camilo ficou mais sossegado; temia que o anônimo fosse ter com Vilela, e a catástrofe viria então sem remédio. Rita concordou que era possível.

- Bem - disse ela -; eu levo os sobrescritos para comparar a letra com a das cartas que lá aparecerem; se alguma for igual, guardo-a e rasgo-a... ${ }^{18}$

No drama burguês, a personagem protagonista encontra a cumplicidade no "outro" para o sucesso de seu objetivo, confirmando a comicidade do texto; neste sentido, Rita desempenha um papel duplo na narrativa: ela é a concretização, a materialização do objetivo de Camilo, como também a necessidade que o movimenta e dá funcionalidade à sua presença e primazia na narrativa; ao mesmo tempo, Rita constitui-se como "o outro" enquanto presença permanente e coadjuvante na peripécia contra Vilela. Nosso herói cômico não age sozinho, Rita acentua o caráter de Camilo e dá vitalidade ao seu drama e desenvolvimento em toda a narrativa, seja como motivo, seja como cúmplice do ingênuo rapaz. A constituição da personagem Rita vai além de sua duplicidade, carrega em si uma tridimensionalidade na medida em que desempenha um papel fundamental para o desenvolvimento da trama: conforme pontuados anteriormente, a descoberta da traição por Vilela não se deve à interferência do destino na trama, mas ao descuido de Rita ao levar à companhia de Vilela o bilhete anônimo. Se

${ }^{18}$ ASSIS, Machado de. A cartomante, cit., p. 138. 
na tragédia ática o fim trágico resulta da interferência do destino na vida do herói, predestinada pela sibila, em "A cartomante" esse fim resulta da ingenuidade das personagens ao aproximarem Vilela da carta, justamente ao tentarem cuidar que o anônimo não os denunciasse a ele. Entre a tragicidade do ato e a profecia feita pela cartomante, há um afastamento que a incapacita de premeditar o final da história. Não há possibilidade premonitória, visto que a tragicidade não resulta da interferência do destino, mas do descuido e da ingenuidade dos amantes. Opera-se no conto o esvaziamento do significado transcendente, tanto no papel da sibila quanto no do destino, como também ocorre a vulgarização da causalidade que motiva a catástrofe; essa vulgarização confirma-se na transferência da catástrofe enquanto resultado da interferência do destino para tornar-se desfecho do descuido das personagens. Com isso, percebemos a tridimensionalidade na constituição da personagem Rita, uma vez que ela é: motivo que movimenta o herói cômico Camilo; coadjuvante na peripécia contra Vilela; e facilitadora da descoberta da traição. Desse modo, como motivo da paixão de Camilo e como causadora da descoberta, Rita traz em si a constituição do amor e da catástrofe, ambiguidade fundamental presente na tragédia ática.

Na trama da narrativa, as ações miúdas que se articulam em direção a uma ação maior - a traição - trazem em si o sentido ambíguo desse gênero misto. Pode-se entender essa ação pelo prisma da comédia, enquanto peripécia das duas personagens contra Vilela. A peripécia reafirma-se pela vulgaridade que a ação carrega; tal vulgaridade define-se pela infidelidade da esposa e do amigo, motivada por uma mesquinhez egoísta com intuito de meramente realizar seus desejos em detrimento dos valores morais e da respeitabilidade de sentimento que a personagem traída nutria por ambos:

Não tardou que o sapato se acomodasse ao pé, e aí foram ambos, estrada fora, braços dados, pisando folgadamente por cima de ervas e pedregulhos, sem padecer nada mais que algumas saudades, quando estavam ausentes um do outro. A confiança e estima de Vilela continuavam a ser as mesmas. ${ }^{19}$

${ }^{19}$ Idem, p. 133. 
Pé e sapato acomodam-se e pisam por cima de qualquer sentimento que apareça à frente. Amor e traição confundem-se em seus significados ideais no contraste com uma realidade limitadora dos desejos e dos amores impossíveis, transferindo ao leitor a responsabilidade de julgar tais ações e comportamentos. Tendenciosamente orientado, o leitor encontra-se diante de duas possibilidades de juízo: defender o amor e a sua realização nos amantes ou apoiar Vilela em sua vingança extremada, que resulta em duplo assassínio. Com isso, a narrativa relativiza seu tom cômico e acentua seu teor trágico ao revelar no desdobramento textual o acaso que leva Rita e Camilo a se apaixonarem. Não é amor à primeira vista, ambos herdam a afeição que Vilela nutre por cada um. Se, para Camilo, o amigo pintava a formosura da esposa, para esta o marido afeiçoava-lhe a amizade de infância que tinha por Camilo; a vinda para a capital e a morte da mãe de Camilo facilitam a intimidade entre os três e o cuidado afetivo com que a mulher de Vilela dedica-se a consolar o amigo órfão; o tempo que passavam juntos a se distrair insinua o afastamento desinteressado do marido, confirmando "o porte grave de Vilela (que) fazia-o parecer mais velho que a mulher". ${ }^{20}$

Tais motivações reduzem o significado de peripécia, característico da comédia, reforçando o acaso desse sentimento por não haver interesse direto de ambos em prejudicar o advogado. Se o amor adúltero dos dois é verdadeiro, não é menos verdadeiro o sentimento de estima que ambos têm pelo marido traído. Amor e estima acentuam a tensão da narrativa e confirmam seu teor trágico.

$\mathrm{Na}$ composição das personagens, a narrativa apresenta-se por meio das estruturas da tragédia: a previsão profética apresentada por Rita, o amor proibido entre os dois, a intervenção do destino e do oráculo no dilema de Camilo são formas do trágico que ganham o leitor, o qual simpatiza com o drama das personagens protagonistas. Vilela aparece na condição de vilão, principalmente pela forma como a narrativa se estrutura, contada a partir dos adúlteros e não da "vítima". O herói é Camilo, não Vilela.

Mas, no movimento irônico de garantir o valor sublime ao melodrama burguês, o narrador opera a tragicomicidade, encenando os elementos que compõem a comédia. Um desses elementos é o rebaixamento das personagens. Se ambos reproduzem o

\footnotetext{
${ }^{20}$ Ibidem.
} 
arquétipo shakespeariano dos amantes, Camilo é apresentado como ingênuo e inexperiente, e Rita, como tonta, apesar de formosa; ambos são adúlteros. Essa operação de rebaixamento das personagens deve-se mais à diluição da composição do "herói", tornando-as comuns e reconhecíveis pelo leitor, do que a apenas torná-las ridículas, com o intuito de provocar o riso. O sublime é acompanhado de perto, ou melhor, está emaranhado com o vulgar, conforme a leitura de Villaça; a "tradução" de Hamlet é feita por Rita "por outras palavras"; o amor de Camilo resulta de um vulgar cumprimento feito a lápis em um cartão de aniversário dado por ela; "não há dúvida de que a ideia do vulgar está se expandindo no conto, e que na outra ponta da escala o narrador vai buscar o sublime para montar - e relativizar - o paradoxo". ${ }^{21}$

Esse paradoxo opera-se pelo segundo procedimento da tragicomédia: a paródia. Ao apresentar o modelo de início, a frase de Hamlet a Horácio depois de sua conversa com o fantasma do rei dinamarquês, seu pai, o narrador o desconstrói e desloca para o cotidiano carioca, quando acentua a "diferença que o fazia por outras palavras". ${ }^{22}$ Hamlet é traduzido pela tonta Rita de modo vulgar. Embora vulgar, a tradução não perde seu sentido primeiro, mas reinscreve a afirmativa em outro contexto, promovendo no leitor uma percepção que se mantém suspensa mesmo depois do término do texto. $\mathrm{O}$ mistério de Hamlet está para além da filosofia, do oráculo, da profecia, da cartomante: mentiria a cartomante? Camilo estava certo ao optar, depois dos vinte anos, por desinteressar-se da fé de infância? Eis a reinscrição que suspende não apenas a narrativa, mas o leitor, no final do texto. Se, em Édipo Rei, a profecia cria angústia e inconsequência em Laio e em Édipo, os quais desafiam o destino, e por isso acabam confirmando-o, em "A cartomante", a profecia cria tranquilidade e negação de si mesma, na confirmação da suposição racional que já deduzira Camilo ao receber o bilhete. A atualização do trágico em Machado, na releitura do papel que desempenha o oráculo, gera a dúvida não apenas quanto ao papel da cartomante, mas quanto ao significado do misticismo no cotidiano burguês e seu papel na tragédia antiga.

Rebaixamento e quebra das expectativas do espectador, apresentadas em "Tractatus" como elementos da comédia, movimentam-se no conto como operações que

\footnotetext{
${ }^{21}$ VILLAÇA, Alcides. Machado de Assis: tradutor de si mesmo, cit., p. 6.

${ }^{22}$ ASSIS, Machado de. A cartomante. In: Obras completas em quatro volumes. v. 2, Rio de Janeiro: Aguilar, 2008. p. 447.
} 
reavaliam a temática do adultério e as condições reais do casamento burguês na sociedade carioca. Vilela é casado com Rita e amigo de Camilo, tornando-se o ponto de contato entre os dois para que ambos se conheçam e se apaixonem. Vilela é apresentado como um homem de porte grave e, embora um ano mais novo que Rita, aparentemente mais velho. Com a morte da mãe de Camilo, entrega a este o seu papel de companheiro de Rita. Embora o narrador não detalhe muito a relação de Vilela e Rita, dá-nos pista do quanto era interessante esse casamento. Esses detalhes, que se escondem na trama do texto, são operados pelo terceiro procedimento da tragicomédia: a ironia. Essa operação processa-se por meio da simetria incongruente observada por Villaça: as personagens da tragédia dão espaço aos melodramáticos Rita e Camilo; a frase de Hamlet para explicar a Horácio a aparição do fantasma traduz-se na vulgar explicação "por outras palavras" da visita de Rita à cartomante e para justificar a mobilidade de Camilo entre desinteresse e o "desejo de crer nas lições das cartas"; a caleça de praça "vale o carro de Apolo"; ${ }^{23}$ o templo de Delfos reduz-se a um imundo cômodo com pouca luz no fundo de uma casa na rua da Guarda Velha; a profecia do destino cercada pelos rituais do sagrado, cujo cumprimento nada pode impedir e ao qual o herói está fadado, resume-se a uma adivinha estimulada por uma nota de dez mil réis, cujas palavras levam o herói a sucumbir, confirmando o oposto da profecia. Essas (as-)simetrias estabelecem a incongruência e sua atualização no drama carioca, criando um desequilíbrio "em favor do silencioso e do não dito". ${ }^{24} \mathrm{Na}$ relação entre dito e não dito, a ironia opera-se por meio das "sobretônicas contextuais", que aumentam a compreensão de seus elementos cognitivos a partir das relações sociais extratextuais. ${ }^{25}$ Ao representar o drama de Camilo e Rita, o narrador o reinscreve entre os vários textos que tratam da temática do adultério, muito em voga no século XIX.

Na crônica publicada em 17 de setembro de 1893, Machado apresenta, juntamente com as notícias da Revolta da Armada, dois anúncios particulares de duas damas, uma senhora e uma jovem. Ambas procuram "um homem honesto que as proteja ocultamente". A partir desse anúncio, o cronista chama-nos a atenção para o verbo e o advérbio - "proteja ocultamente" - para desenvolver uma análise acurada das relações amorosas e de seus trâmites econômicos, que marcam o casamento burguês:

\footnotetext{
${ }^{23}$ VILLAÇA, Alcides. Machado de Assis: tradutor de si mesmo, cit., p. 6.

${ }^{24}$ HUTCHEON, Linda. Teoria e política da ironia, cit.

${ }^{25}$ Idem, p. 206.
} 
Vindo aos anúncios, notai em ambos eles o verbo e o advérbio: "Que as proteja ocultamente". Proteger é sinônimo de amar - eufemismo, dirão as pessoas graves -, uma corrutela, replicarão as pessoas leves. $\mathrm{Eu}$ digo que é uma revivescência. $\mathrm{O}$ amor antigo era simples proteção. Em vez da sociedade em comandita, a que a civilização o trouxe, com lucros iguais, era um ato de dominação do homem e da submissão da mulher. Vede os costumes bíblicos, as doutrinas muçulmanas, as instituições romanas e gregas. ${ }^{26}$

Ao tratar das relações amorosas burguesas, contrapondo-as às formas "primitivas" do amor, o cronista esvazia o sentido primeiro delas, sua semântica de dominação como sinônimo de proteção - verdadeiro sentido do amor - e enxerta nelas as transações econômicas em suas comanditas em lucros iguais, enquanto procedimento de profanação do sagrado. O casamento, materialização do amor, cujo sentido primeiro e sagrado é a proteção, entendida como dominação masculina, recontextualiza-se na sociedade carioca do século XIX como transação econômica. Essa profanação é similar à da sibila que se sente estimulada em seus presságios ao receber de Camilo a nota de dez mil réis como forma de pagamento, valor cinco vezes maior do que costumava receber. Tanto em um quanto em outro, o dito (procurar cavalheiro rico/pagar a profecia com uma nota de dez mil-réis) e o não dito (profanação do sagrado - casamento e profecia) criam uma terceira nota e operam as "arestas" da ironia. ${ }^{27}$ Há nesse procedimento o rebaixamento do sagrado, em que valores metafísicos e transcendentes perdem seu lugar no "Além" e se justificam como processo materialista em um modelo capitalista de sociedade. Por meio disso, questiona-se o real sentido da profecia que não se cumpre ou do casamento que não se sustém, pois ambos estruturam-se sobre promessas jamais cumpridas.

Ao relermos o conto a partir do olhar do cronista de 1893, ponderamos algumas informações que aparecem ao longo da narrativa, como pistas para compreender a condição de submissão de Rita. Não há dúvidas do amor que ela devota a Camilo e da reciprocidade desse amor. Rita herda de Vilela a admiração que este tem por Camilo e a primeira informação que dá ao jovem é de o quanto o marido falava

\footnotetext{
${ }^{26}$ ASSIS, Machado de. A Semana. Org. por John Gledson. São Paulo: Hucitec, 1996. p. 298-299.

${ }^{27}$ HUTCHEON, Linda. Teoria e política da ironia, cit.
} 
sobre ele. A ausência do marido e a companhia do amigo que o substitui nas horas de lazer são formas de rebaixamento do que era destino para se tornarem elementos de constituição histórica e cultural. Não é o destino perverso que marca a história dos dois, mas as condições reais e materiais que a estimulam e a efetivam, assim como a profecia não resulta da intervenção do destino, mas do interesse puramente econômico da sibila em utilizar-se da fé como recurso para sobrevivência à margem de uma sociedade perversa e excludente.

Em "A cartomante", Machado reatualiza os elementos retóricos e poéticos da tragédia e da comédia na forma tragicômica, para operar um novo sentido e uma nova leitura da temática do adultério e do casamento presentes na literatura canônica e de folhetim e, com isso, reinscrever novos procedimentos e novas concepções sobre temas bastante visitados pela tradição literária. Sua confirmação como escritor moderno devese exatamente a ele não encerrar a discussão, pelo contrário, a ele reativar o tema numa nova perspectiva material e histórica dos procedimentos estético-literários na ordem burguesa de sua época.

Referências:

ARISTÓTELES. Poética. São Paulo: Ed. Cultrix, 1981.

Tratado Coisliniano. In: Poética. Tradução feita pelo grupo de pesquisa do projeto OUSIA. Coord. Prof. Dr. Fernando Santoro. Disponível online no endereço: <http://www.ifcs.ufrj.br/ fsantoro/ousia/traducao_coisliniano.html> (Acessado em 12 de março de 2008).

ASSIS, Machado de. A cartomante. In: . Obras completas em quatro volumes. v. 2, Rio de Janeiro: Aguilar, 2008.

A Semana. Org. por John Gledson. São Paulo: Hucitec, 1996.

BENDER, Ivo C. Comédia e riso: uma poética do teatro cômico. Porto Alegre: EDIPUCRS, 1996. 
HUTCHEON, Linda. Teoria e política da ironia. Belo Horizonte: Editora UFMG, 2000.

. Uma teoria da paródia: ensinamentos das formas de arte do século XX. Lisboa: Edições 70, 1989.

PLAUTUS, Titus Maccius. Anfitrião. Lisboa: Edições 70, 1993.

SOUZA, Ronaldes de Melo e. O romance tragicômico de Machado de Assis. Rio de Janeiro: EdUERJ, 2006.

SZONDI, Peter. Ensaio sobre o trágico. Rio de Janeiro: Jorge Zahar Ed., 2004.

VILLAÇA, Alcides. Machado de Assis: tradutor de si mesmo. In: Revista Novos Estudos, n. 51, julho de 1998. São Paulo, 1998.

Dário Ferreira Sousa Neto é mestre em Literatura Brasileira pela Universidade de São Paulo, onde defendeu, no fim de 2008, a dissertação "Memórias de cotidiano e saberes sujeitados: análise das crônicas A + B de Machado de Assis", sob orientação do Prof. Dr. João Adolfo Hansen e com auxílio da CAPES. Atualmente, é doutorando em Literatura Brasileira na Universidade de São Paulo. E-mail: <darioneto@usp.br> 